\title{
Dynamic and Static Volatility Interruptions: Evidence from the Korean Stock Markets ${ }^{\dagger}$
}

\author{
Kyong Shik Eom ${ }^{1, *}$, Kyung Yoon Kwon ${ }^{2}$, Sung Chae La $^{3}$ and Jong-Ho Park ${ }^{4}(\mathbb{D}$
}

check for

updates

Citation: Eom, Kyong Shik, Kyung

Yoon Kwon, Sung Chae La, and

Jong-Ho Park. 2022. Dynamic and

Static Volatility Interruptions:

Evidence from the Korean Stock

Markets. Journal of Risk and Financial

Management 15: 105. https://

doi.org/10.3390/jrfm15030105

Academic Editor: W. Brent Lindquist

Received: 27 January 2022

Accepted: 22 February 2022

Published: 25 February 2022

Publisher's Note: MDPI stays neutral with regard to jurisdictional claims in published maps and institutional affiliations.

Copyright: (C) 2022 by the authors. Licensee MDPI, Basel, Switzerland. This article is an open access article distributed under the terms and conditions of the Creative Commons Attribution (CC BY) license (https:// creativecommons.org/licenses/by/ $4.0 /)$.
1 CRMR, Department of Economics, University of California at Berkeley, Berkeley, CA 94720, USA

2 Strathclyde Business School, University of Strathclyde, Glasgow G1 1XQ, UK; kyung.kwon@strath.ac.uk

3 Korea Exchange, Busan 48400, Korea; schaela@krx.co.kr

4 Department of Business Administration, Sunchon National University, Sunchon 57922, Korea; schrs@scnu.ac.kr

* Correspondence: kseom2@gmail.com

$+\quad$ The authors are very grateful for access to a data set provided by the KRX, and for helpful discussions with Robert M. Anderson and seminar participants at the University of California at Berkeley. This paper was previously circulated under the title "The role of dynamic and static volatility interruptions: Evidence from the Korean stock markets". All errors are the responsibility of the authors.

\begin{abstract}
We conducted a comprehensive analysis on the sequential introductions of dynamic and static volatility interruptions (VIs) in the Korean stock markets. The Korea Exchange introduced VIs to improve price formation, and to limit risk to investors from brief periods of abnormal volatility for individual stocks. We found that dynamic VI is effective in price stabilization and discovery, while the effect of static VI is limited. The static VI functions similarly to the pre-existing price-limit system; this accounts for its limited incremental benefit.
\end{abstract}

Keywords: volatility safeguards; volatility interruption; call auction; price stabilization; price discovery

JEL Classification: G10; G18; G20

\section{Introduction}

A volatility interruption (VI), a subcategory of volatility safeguards, is a form of trading pause during which order execution is suspended briefly, while order submissions and cancellations are still allowed. This sophisticated microstructure mechanism has been designed to provide cooling-off periods and effective price discovery during brief periods of abnormal volatility for individual stocks. Generally, a VI consists of two components: dynamic and static. Dynamic VI is invoked when a price fluctuation due to a single order exceeds a predetermined threshold range, e.g., $\pm 2 \%$. Static VI is activated when the cumulative price fluctuation due to multiple orders and transactions exceeds a predetermined threshold range, e.g., $\pm 10 \%$. If the potential execution price exceeds either the dynamic or static threshold range, all transactions for the individual stock are stopped for a predetermined short period of time, e.g., 2 to $5 \mathrm{~min}$, and trading resumes with a call auction that includes a random-end (RE) trading mechanism (Guillaumie et al. 2020). ${ }^{1}$

Since its early days, the Korea Exchange (KRX) has used a price-limit system, another form of trading pause, limiting price movements for the day to a specified percentage (e.g., $\pm 15 \%$ from 7 December 1998 to 14 June 2015). On 1 September 2014, the KRX adopted only the dynamic component of VI (without RE mechanism), while leaving the price limit unchanged. Then, on 15 June 2015, the exchange added the static component of VI, expanded the price limit to $\pm 30 \%$, and simultaneously added the RE mechanism to both dynamic and static VIs (see Figure 1). As a result, the KRX has not only VIs, but also a price-limit system. ${ }^{2}$ The KRX documents state that the purpose of VIs is to improve price formation, and to limit risk to investors from brief periods of abnormal volatility 
for individual stocks. In this paper, we investigate the separate contributions of the two components of VI to price stabilization and price discovery. In addition, we study the separate contributions of the newly-introduced VIs and the extant price-limit system. To the best of our knowledge, this paper is the first research on these subjects.

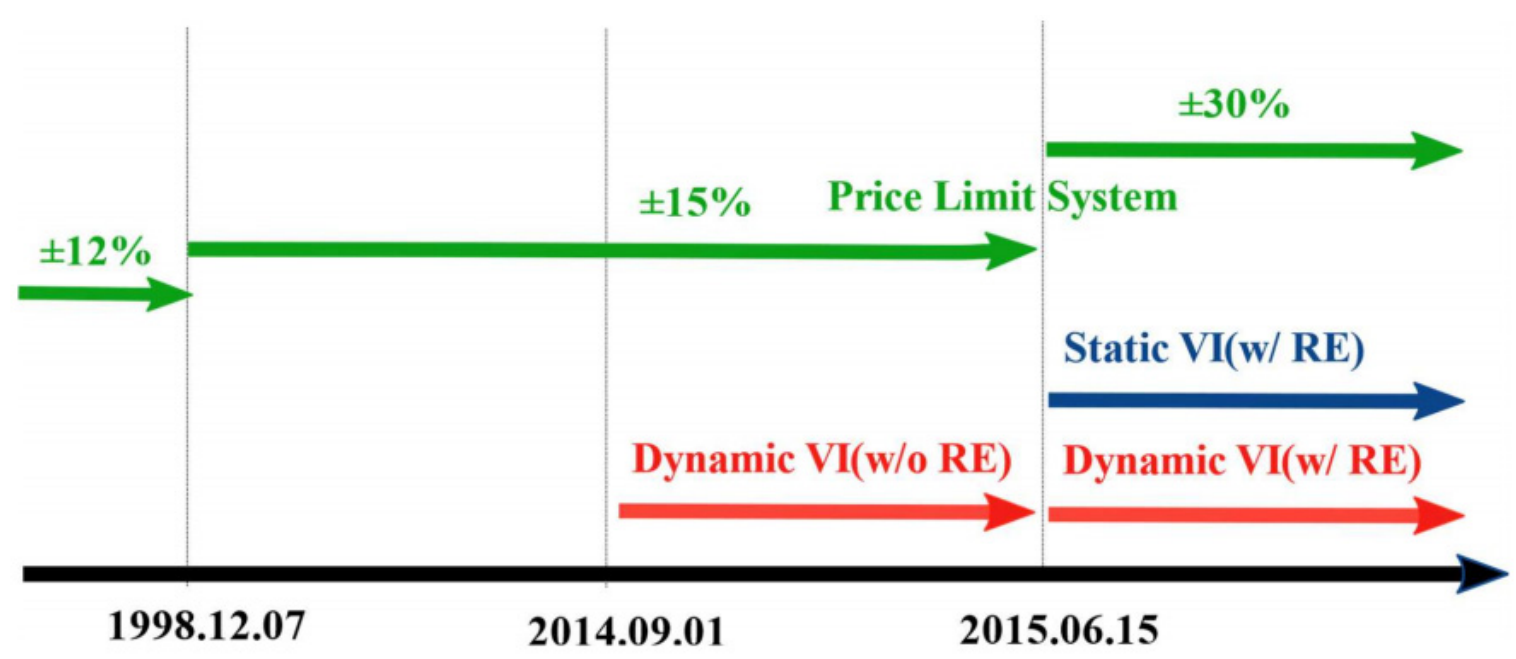

Figure 1. Time line in the KRX. The KRX has used a price-limit system to limit price movements for the day to a specified percentage (e.g., $\pm 15 \%$ from 7 December 1998 to 14 June 2015). On 1 September 2014, the KRX adopted dynamic VI (without RE mechanism), while leaving the price limit unchanged. Then, on 15 June 2015, the exchange added static VI, expanded the price limit to $\pm 30 \%$, and simultaneously added RE mechanism to both dynamic and static VIs.

To implement these research objectives, we examine the effects of two events, the sequential introductions of dynamic and static VIs. We focus on 45 trading days before and after each event and investigate the effects of the events, utilizing four different approaches. First, we begin with the descriptive statistics on dynamic and static VI occurrences and their relationships to firm characteristics to see the conditions under which VI is more likely to be invoked. Second, we examine the price-stabilization effects of VIs using a binomial distribution analysis of two consecutive price changes; if dynamic (static) VI effectively stabilizes the price, then two price changes, the one between the last execution (last call auction) price and the potential execution price and the other one between the potential execution price and the call auction price, will show a reversal. ${ }^{3}$ For a robustness check, we also use a panel-data analysis, controlling for endogenous variables. Third, we evaluate the price-discovery effect using two-step regressions. Fourth, using panel logit regression analysis, we examine the relation between the occurrences of VI and those of the price-limit hit, considering that static VI and the price-limit system have similar functionalities.

In this paper, we analyzed 1676 stocks in 2014 and 1685 stocks in 2015, which are listed on KOSPI and KOSDAQ markets in the KRX. ${ }^{4}$ The following are our empirical results. First, as a preliminary result, we confirm our expectation that both dynamic and static VIs are invoked more often in small, low-priced, and highly volatile stocks. We also find that static VI occurs, a bit surprisingly, more to liquid stocks whereas dynamic VI occurs, as expected, more to illiquid stocks. Second, we find that the contribution of dynamic VI to price stabilization is much larger than that of static VI, and that the price-stabilization effect of dynamic VI is significantly higher during continuous trading than during the closing auction. Third, we find that the contribution of dynamic VI to price discovery is also substantially larger than that of static VI, and both the price-stabilization and pricediscovery effects of dynamic VI began immediately after its introduction and were not substantially affected by the introduction of static VI; these effects were not altered by the addition of an RE mechanism to dynamic VI. Fourth, we find that static VI and the price-limit system are triggered by the same kind of circumstances. Combining all the above 
results, we can draw the following policy implication: VIs are very useful and effective in both price stabilization and discovery in the stock market. In addition, the KRX should consider removing the pre-existing price-limit system, which is now redundant with the static VI.

Since the Brady (1988) Report, academics have used the terminology, circuit breakers, in a broad sense, encompassing a variety of individual-stock trading halts/pauses and price-limit systems in addition to market-wide trading halts. Here, trading halts suspend all order book activity, whereas trading pauses only suspend order execution. Individual trading halts/pauses consist of rule-based trading pauses (e.g., VIs) as well as discretionary trading halts (e.g., voluntary trading halts occurring when an individual firm requests that trading be suspended before the release of material information, or the decision of an exchange to suspend trading in a stock which exhibits extreme order imbalances). Except for market-wide trading halts, all of these circuit breakers apply to individual stocks. Recently, algorithmic and high-frequency trading has grown to constitute a high proportion of transactions on global stock markets, and liquidity can evaporate quickly as a result (The Government Office for Science 2012). Consequently, VIs have become a very important tool for price stabilization and investor protection. Since the 2007 implementation of the Markets in Financial Instruments Directive (MiFID) in Europe and the 2010 Flash Crash in the U.S., VIs and their variants have been introduced or have substantially replaced pre-existing price-limit systems for individual stocks in global stock exchanges (Guillaumie et al. 2020). A good example is the U.S., which introduced Limit Up/Limit Down (LULD), ${ }^{5}$ a simpler version of the VIs, after the Flash Crash. Circuit breakers have become a focal point of the financial policy debate again since the first peak of the COVID-19 pandemic in spring 2020, when they were triggered in record levels in numerous markets worldwide (Alderighi et al. 2021).

This paper makes the following detailed contributions to the existing literature; see Section 2 for details. First, the sequential introductions of dynamic and static VIs allow us to separate the effects of these two components of VIs and compare their effectiveness. Moreover, the pre-existing price-limit system on the Korean stock markets allows us to separate the effects of price-limit systems and VIs. Hence, we can separate the effects of dynamic VI, static VI, and price-limit systems, which has not been possible in previous studies. Second, the sequential introductions of dynamic and static VIs allow us to properly measure the difference in market state with a dynamic VI versus no VI, and with dynamic and static VI versus only dynamic VI. Thus, we avoid one of the main weakness of the broadly-defined circuit-breaker literature, the need to control for an artificial counterfactual that captures what the status of the market would have been if a circuit breaker had not been triggered. ${ }^{6}$ Third, our results from the sequential introductions of dynamic and static VIs can provide some insights for the mixed results in the existing literature on the efficacy of a VI. Fourth, unlike previous studies, we analyze the price-stabilization effect not only in the continuous trading session, but also in the opening and closing sessions, and present the differences. ${ }^{7}$

The remainder of the paper is organized as follows. Section 2 presents the literature review and Section 3 briefly describes the VIs in the Korean stock markets. Section 4 discusses the sample period and the data. Section 5 reports the distribution of static and dynamic VIs and their relations with firm characteristics. Sections 6 and 7 present the empirical methodology and results on price stabilization and price discovery, respectively. Section 8 examines the relationship between the occurrences of VI and those of price-limit hits. We conclude the paper in Section 9.

\section{Literature Review}

Most of the related academic literature, thus far, has focused on market-wide circuit breakers, discretionary trading halts, and price-limit systems, ${ }^{8}$ while there has been scant study of VIs. All of the VI studies of which we are aware analyzed their invocations only during the continuous trading session. 
Abad and Pascual (2010) examine the static VI on the Spanish Stock Exchange (SSE) SIBE platform from June 2001 to December 2003. They report that volatility and trading activity return to normal conditions within $90 \mathrm{~min}$ after the resumption of post-event trading, and that the adverse-selection cost is largest when the VI is invoked, but then resolves in $30 \mathrm{~min}$. More interestingly, they find price continuation during the call auction period and price reversal after the post-event trading. These results imply that in the SSE, the static VI makes the stock price more volatile rather than more stable.

Zimmermann (2013) studies the price stabilization and discovery effects of VIs on Deutsche Börse (DB) Xetra platform between January 2009 and January 2012. He does not distinguish between dynamic and static VI, but includes the RE session induced by a VI occurrence in his test window and utilizes Xetra midday auctions as a control group. According to his results, VIs play a major role in shaping post-VI occurrence market quality, resolving $36 \%$ of the price uncertainty on average. Recently, analyzing VI occurrences on 40 EU trading venues from April 2016 to December 2016, Guillaumie et al. (2020) generally confirm Zimmermann's results on price-stabilization and price-discovery effects. They also report that, for cross-listed stocks, "trading activity on the satellite market decreases drastically and liquidity dries up as investors refrain from trading, waiting for the reference market to set the [VI] auction price". ${ }^{9}$

On the other hand, Brugler et al. (2018) investigate static VI on the London Stock Exchange (LSE) from July 2011 to August 2011. They document that the economic effects of static VI vary depending on the market state. Specifically, they report that static VI can be an effective tool for promoting market-wide stability in falling markets. Hautsch and Horvath (2019), however, report that the defunct single-stock trading pauses (SSTP) and current LULD mechanisms, adopted by Nasdaq after the 2010 Flash Crash, do not effectively stabilize the markets but rather cause extra volatility after the mechanism is introduced. They argue that "these are likely situations where trading pauses are triggered by nonsystematic local bursts of volatility, which are, however, quickly attenuated by the market itself. In these cases, a trading interruption obviously causes more harm than good [ ... ]". However, they also insist that their findings "do not rule out that in some (extreme) cases, trading pauses still fulfill an important role as preventers of excessive price changes. In these rare situations, trading pauses are indispensable breakers of local price trends, which prevent markets from flash crashes". Recall that the LULD is an extreme version of static VI, mainly designed to prevent a recurrence of the Flash Crash in 2010.

\section{Volatility Interruptions in the Korean Stock Markets}

The purpose of a dynamic VI is to alleviate the temporary volatility caused by a sudden imbalance of supply and demand resulting from a single order. In Korea, a dynamic VI is invoked when the difference between a stock's most recent execution price and potential execution price exceeds a specified price range ( $\pm 2 \sim 6 \%$ of the most recent price). The thresholds for invoking a dynamic VI are $2 \%$ (closing call auction) and 3\% (continuous trading) for constituent stocks in the KOSPI 200 index; $4 \%$ (closing call auction) and $6 \%$ (continuous trading) for all other KOSPI- and KOSDAQ-listed stocks. A dynamic VI is effective during the continuous trading session, closing call auction, and after-hours trading, but not during the opening call auction.

The purpose of a static VI is to mitigate cumulative price movement during a trading day resulting from one or more orders. In Korea, a static VI is triggered when the difference between the price at the previous call auction and the potential execution price exceeds $\pm 10 \%$, for all stocks on the KOSPI and KOSDAQ markets. A static VI is effective during the opening call auction, continuous trading session, and closing call auction, but not during after-hours trading.

When a dynamic or static VI is invoked during a continuous trading session, all transactions in the stock cease and a call auction is triggered, with a random end between 2 min and $2 \mathrm{~min} 30 \mathrm{~s}$; at the random end, the buy and sell orders are crossed and executed, and the continuous trading session resumes. The VIs are not applied during market-wide 
circuit breakers or intraday call auctions after a discretionary trading halt. The VIs apply to products including common stocks, depositary receipts (DRs), and exchange-traded funds (ETFs), but do not apply to products scheduled to be delisted or designated as temporarily overheated.

The introduction of VIs on the KRX differed from those in European countries. The KRX sequentially adopted VIs on top of the pre-existing price-limit system. In contrast, the European countries generally did not utilize price limits, and generally introduced dynamic and static VIs simultaneously (Sifat and Mohamad 2019). The sequential introductions in Korea allow us to separate the effects of dynamic and static VIs, as well as the effects of static VI and price-limit systems.

\section{Sample Period and Data}

The overall analysis is based on the two events, the sequential introductions of dynamic and static VIs. The dynamic VI was introduced on 1 September 2014 while the static VI was introduced on 15 June $2015 .{ }^{10}$ To choose appropriate sample periods to control for other possible effects and avoid exogenous shocks, we first examined the market movement around these events using the representative market index, the KOSPI 200 index, and the market volatility index known as the V-KOSPI 200 index.

In Figure 2, Panels A and B show the time-series of the KOSPI 200 index and the V-KOSPI 200 index from January 2014 to January 2016, respectively. There was a large drop in the KOSPI 200 index and an abrupt large hike of the V-KOSPI 200 index in the final days of August 2015. The turmoil on the Shanghai Stock Exchange (SSE) in late August 2015 and the "mini Flash Crash" (related to the LULD rule) on the New York Stock Exchange (NYSE) on 24 August 2015 may have contributed to the increases in the V-KOSPI 200 index around the end of August 2015.

To avoid the effects of these exogenous shocks, we chose to end the sample period (hereafter, "post-event period in 2015") for the introduction of static VI on 21 August 2015. Thus, it runs from 15 June 2015 to 21 August 2015, a total of 45 trading days. Accordingly, we chose the "pre-event period in 2015" to include 45 trading days, from 8 April 2015 to 12 June 2015. For consistency, we chose to include 45 trading days before and after the 2014 dynamic VI event in our sample period. Accordingly, the period before the 2014 event (hereafter, "pre-event period in 2014") is from 27 June 2014 to 29 August 2014 and the period after the 2014 event (hereafter, "post-event period in 2014") is from 1 September 2014 to 7 November 2014.

We included all common stocks listed on the KOSPI and KOSDAQ markets, but excluded (1) DRs, ETFs, real estate investment trusts (REITs), and special purpose acquisition companies (SPACs), (2) newly-listed and delisted stocks, and instruments that changed listings (e.g., from KOSDAQ to KOSPI) during the sample periods, (3) stocks which traded less than 40 days before or after the event. Consequently, our sample data include 1676 stocks in 2014 and 1685 stocks in 2015. We used trade and quote (TAQ) data for individual stocks and daily data for indices. 
Panel A. KOSPI 200 index KOSPI200
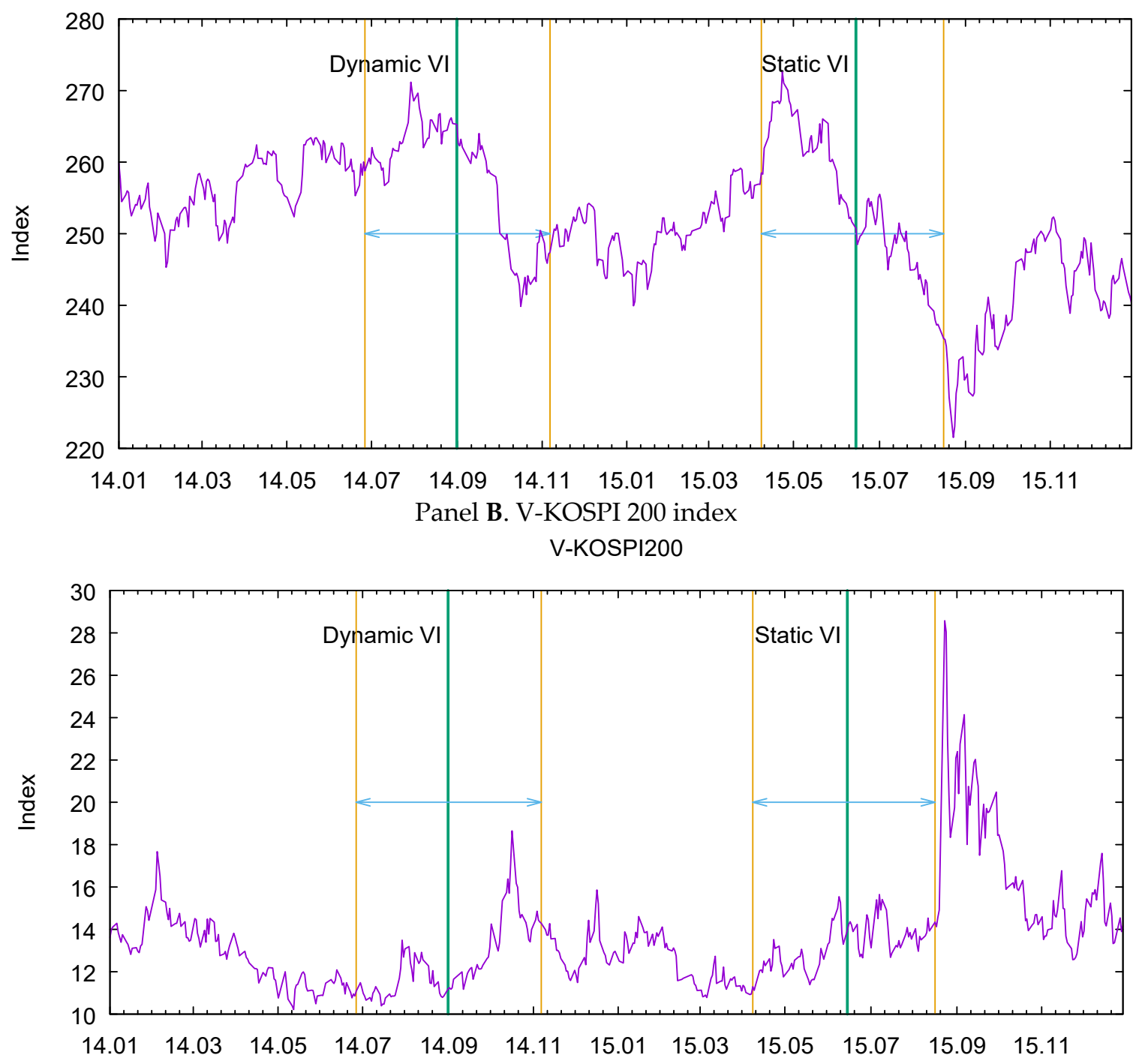

Figure 2. Time-series of the KOSPI 200 index and the V-KOSPI 200 index. This figure depicts the stock market movement from January 2014 to January 2016. Panel (A) and Panel (B) show the time-series of a market index (KOSPI200) and a market volatility index (V-KOSPI200), respectively. The horizontal axis indicates the date (yy.mm) and the vertical axis indicates the index value.

\section{Descriptive Statistics on VI Occurrences}

As our preliminary analysis, we investigated the distribution of dynamic and static VI occurrences and their relationships to firm characteristics during the sample period.

Table 1 provides the summary statistics on stock characteristics (Panel A) and VI occurrences (Panels B and C). First, we categorize sample stocks into two groups, one with stocks experienced the VI at least once during the sample period and others. Then, we compute the average firm characteristics of each group. For firm characteristics, we employ trading volume in shares (VOLUME_SHARE), trading volume in KRW (VOLUME_VALUE), firm size measured by market capitalization (MKT_CAP), and the closing price (PRC). We also use volatility measured by the standard deviation of daily returns (STD_DEV) and the daily highest and lowest price (INTRA_VOL). 
Table 1. Summary statistics. This table presents the summary statistics of our data during the sample period. Panel A reports the characteristics of stocks with and without VI occurrences during the sample period, Panel B shows the descriptive statistics on dynamic and static VI occurrences, and Panel C presents the distribution of VI occurrences across prices in each subsample period. In this table, the results for the pre-event (post-event) period in 2015, which is from 8 April 2015 to 12 June 2015 (15 June 2015 to 17 August 2015), is denoted as "2015" and "Pre" ("Post"). The results for the post-event period in 2014, which is from 1 September 2014 to 7 November 2014, is denoted as "2014" and "Post". The columns assigned as "Dynamic" and "Static" indicate the descriptive statistics on dynamic and static VI occurrences, respectively. VOLUME_SHARE (VOLUME_VALUE) indicates daily trading volume in shares (in million Korean Won, KRW) and MKT_CAP is market capitalization in million KRW. $P R C$ is the closing price in KRW and for volatility measure, $S T D \_D E V$ is the standard deviation of daily returns and INTRA_VOL is the intraday volatility measured by the daily highest and lowest price.

\begin{tabular}{|c|c|c|c|c|}
\hline & \multirow{3}{*}{$\begin{array}{c}2014 \\
\text { Post } \\
\text { Dynamic }\end{array}$} & \multicolumn{3}{|c|}{2015} \\
\hline & & \multirow{2}{*}{$\begin{array}{c}\text { Pre } \\
\text { Dynamic }\end{array}$} & \multicolumn{2}{|c|}{ Post } \\
\hline & & & Dynamic & Static \\
\hline \multicolumn{5}{|c|}{ Panel A. Descriptive statistics of stocks with and without VI occurrences } \\
\hline \multicolumn{5}{|c|}{ Stocks with VI occurrences } \\
\hline Number of stocks & 435 & 525 & 550 & 1119 \\
\hline VOLUME_SHARE & $375,230.7$ & $528,551.2$ & $388,946.3$ & $740,847.3$ \\
\hline VOLUME_VALUE & 1473.7 & 3879.7 & 4467.0 & 5893.0 \\
\hline$M K T \_C A \bar{P}$ & $243,668.5$ & $337,647.3$ & $586,870.7$ & $450,687.2$ \\
\hline$P R C$ & $24,570.5$ & $24,569.9$ & $38,497.0$ & $32,494.7$ \\
\hline$S T D \_D E V$ & 5.0282 & 5.9514 & 6.2306 & 6.2951 \\
\hline INTRA_VOL & 3.1512 & 3.8717 & 3.9710 & 4.1536 \\
\hline \multicolumn{5}{|l|}{ Stocks without VI occurrences } \\
\hline Number of stocks & 1241 & 1160 & 1135 & 566 \\
\hline VOLUME_SHARE & $421,884.7$ & $580,600.0$ & $650,133.4$ & $216,985.5$ \\
\hline VOLUME_VALUE & 4641.6 & 7042.2 & 6144.9 & 5012.4 \\
\hline$M K T \_C A P$ & $933,070.9$ & $1,052,214.8$ & $923,792.8$ & $1,531,739.7$ \\
\hline$P R C$ & $31,892.9$ & $36,415.6$ & $32,190.6$ & $37,717.4$ \\
\hline$S T D \_D E V$ & 4.2295 & 4.7429 & 5.0159 & 3.6671 \\
\hline INTRA_VOL & 2.7551 & 3.0821 & 3.2525 & 2.1692 \\
\hline \multicolumn{5}{|l|}{ Panel B. VI occurrences } \\
\hline $\begin{array}{l}\text { Number of stocks with at least } \\
\text { one VI occurrence }\end{array}$ & 435 & 525 & 550 & 1119 \\
\hline Total number of VI occurrences & 1068 & 958 & 1113 & 5796 \\
\hline $\begin{array}{l}\text { Number of VI occurrences per } \\
\text { stock }\end{array}$ & 0.64 & 0.57 & 0.66 & 3.44 \\
\hline \multicolumn{5}{|c|}{ Panel C. Total number of VI occurrences based on the last execution price prior to the occurrence } \\
\hline \multicolumn{5}{|c|}{ Price $(K R W)$} \\
\hline$<1000$ & 155 & 53 & 66 & 422 \\
\hline $1000 \leq$ and $<5000$ & 568 & 452 & 438 & 2043 \\
\hline $5000 \leq$ and $<10,000$ & 156 & 188 & 214 & 1034 \\
\hline $10,000 \leq$ and $<50,000$ & 141 & 189 & 234 & 1680 \\
\hline $50,000 \leq$ and $<100,000$ & 16 & 39 & 58 & 271 \\
\hline $100,000 \leq$ & 32 & 37 & 103 & 346 \\
\hline
\end{tabular}

Panel A suggests that the introductions of dynamic and static VIs seem to cause no significant changes in firm characteristics. Our results show that small, illiquid, and volatile firms tend to experience dynamic VI, whereas small and volatile but more liquid firms appear to experience static VI more frequently. In untabulated results, static VI occurrences are positively correlated with liquidity variables, while dynamic VI occurrences are negatively correlated. The negative relation of dynamic VI occurrences with liquidity 
variables is rather intuitive: the prices of illiquid stocks tend to fluctuate more, and thus dynamic VI is more frequently triggered in those stocks. Meanwhile, the positive relation of static VI occurrences seems to be related to a difference of opinion among traders (Diether et al. 2002; Eom et al. 2017), since static VI is associated with cumulative price changes. A large trading volume caused by traders with differing opinions may contribute to the occurrence of static VI.

Panel B of Table 1 provides the descriptive statistics on dynamic and static VI occurrences during the sample period. It shows that dynamic VI seems to occur quite steadily across subperiods. Static VI, newly implemented over the post-event period in 2015, is more frequently activated than dynamic VI over the corresponding period. Both the total number of static VI occurrences and those of VI's per stock are almost four times, respectively, larger than those of dynamic VI occurrences.

Lastly, Panel C of Table 1 presents the distribution of VI occurrences across prices in each subsample period. Regardless of subsample periods, dynamic and static VIs show similar distributional patterns across prices. Specifically, most VIs occur in stocks whose prices are between $1000 \mathrm{KRW}^{11}$ and 50,000 KRW and particularly to stocks with relatively lower prices between $1000 \mathrm{KRW}$ and $5000 \mathrm{KRW}$. The number of VI occurrences is substantially lower for stocks with extremely low prices, lower than $1000 \mathrm{KRW}$, and stocks with prices higher than 50,000 KRW. After the introduction of static VI, the distribution of dynamic VI becomes somewhat flatter.

\section{Price-Stabilization Effect}

Price stabilization was one of the KRX's two key goals in introducing VIs. To evaluate the price-stabilization effect of VIs, we conducted three analyses.

\subsection{Comparison of the Intraday Volatility before and after the VI Occurrence}

First, as a simple and straightforward approach, we compared the intraday volatility during one hour before the VI occurrence with that during one hour after the VI occurrence. In particular, within the given one hour (before or after the VI is invoked), we observe the highest (High) and the lowest price (Low) of the given stock and calculate the intraday volatility by $(H i g h-$ Low $) /\left\{\frac{\text { High }+ \text { Low }}{2}\right\} .{ }^{12}$ Then we test whether the intraday volatility is significantly reduced after the VI is invoked. For this analysis, we use stocks that experienced at least a VI occurrence and were traded more than once between 10:00 and 14:00.

Table 2 presents the volatility during one hour before and after the VI occurrence, and the change in volatility after the VI occurrence. Our results show that both dynamic and static VIs significantly reduce the volatility in all subperiods, and the reduction in volatility after the occurrences for dynamic VI is much larger than that for static VI. Specifically, the difference in volatility ranges for a static VI is less than half of the reduction that a dynamic VI generates in the same sample period. These results suggest that dynamic VI more effectively stabilizes the price than static VI.

\subsection{Binomial Distribution Analysis}

Second, our main approach evaluates the stabilization effect of VIs using a binomial distribution analysis applied to an event study. ${ }^{13}$ According to our binomial distribution analysis, if dynamic (static) VI effectively stabilizes the price, then two consecutive price changes, the one between the last execution (last call auction) price and the potential execution price and the other one between the potential execution price and the call auction price, will tend to show a reversal. Put more specifically, dynamic (static) VI is invoked when the difference between the last execution (last call auction) price and the potential execution price exceeds the predetermined level. It is based on the assumption that the potential execution price reflects a temporary imbalance of supply and demand. ${ }^{14}$ Consequently, if dynamic VI contributes to price stabilization, then the call auction price should become larger (smaller) than the potential execution price if the potential execution 
price was smaller (larger) than the last execution price. For static VI, the same statement holds provided that the last execution price is replaced by the last call auction price. ${ }^{15}$ In other words, a reversal in these two price differences, the one between the last call auction price and the potential execution price and the other one between the potential execution price and the call auction price, is an indication of price stabilization.

Table 2. Reduction in intraday volatility after VI occurrence. This table presents the results of comparing the intraday volatility during one hour before the VI occurrence ("Before VI") with that during one hour after the VI occurrence ("After VI"). Within the given one hour (before or after the VI occurrence), we observe the highest (High) and the lowest price (Low) of the given stock and calculate the intraday volatility by $(H i g h-L o w) /\left\{\frac{H i g h+L o w}{2}\right\}$. For this analysis, we use stocks that experienced at least one VI occurrence and were traded more than once between 10:00 and 14:00. The rightmost column ("Difference") presents the volatility difference between Before VI and After VI. The positive number implies that the intraday volatility is reduced after the VI occurrence. ${ }^{* *}$ denotes $1 \%$ statistical significance.

\begin{tabular}{ccccc}
\hline & $\begin{array}{c}\text { No. of } \\
\text { Observations }\end{array}$ & Before VI & $\begin{array}{c}\text { After } \\
\text { VI }\end{array}$ & $\begin{array}{c}\text { Difference } \\
(p \text {-Value })\end{array}$ \\
\hline Dynamic VI: Post-event in 2014 & 193 & 0.0756 & 0.0501 & $\begin{array}{c}0.0255^{* * * *} \\
(0.0000)\end{array}$ \\
Dynamic VI: Pre-event in 2015 & 162 & 0.0833 & 0.0542 & $\begin{array}{c}0.0291^{* * *} \\
(0.0000)\end{array}$ \\
Dynamic VI: Post-event in 2015 & 258 & 0.0936 & 0.0588 & $\begin{array}{c}0.0348^{* * *} \\
(0.0000)\end{array}$ \\
Static VI: Post-event in 2015 & 2852 & 0.0855 & 0.0725 & $\begin{array}{c}0.0130^{* * *} \\
(0.0000)\end{array}$ \\
\hline
\end{tabular}

To test this, we take two steps. First, we compare the number of reversals in price changes (column B in Table 3), which indicates price stabilization, with the number of continuations in price changes (column C in Table 3). If the potential execution price accurately reflects information available to the market, then the probability of reversal should be equal to the probability of continuation. ${ }^{16}$ If the proportion of reversals significantly exceeds 0.5 , then it implies that the VIs effectively stabilize the price. We find that the proportion of reversals is indeed statistically significantly greater than 0.5 for dynamic VI for all subperiods and trading sessions. However, for static VI, it statistically significantly exceeds 0.5 only during the continuous trading, not during the opening and closing call auctions (column E in Table 3).

Next, we calculate the percentage measures of price stabilization and continuation. Each of these is calculated by averaging I (call auction price - potential execution price) $\times$ $100 /$ (potential execution price - last execution or last call auction price) I over the set of reversals and continuations, respectively (columns $F$ and $G$ of Table 3). We also calculate the net price-stabilization effect by averaging - (call auction price - potential execution price $) \times 100 /$ (potential execution price - last execution or last call auction price) over the combined set of reversals and continuations (column $\mathrm{H}$ of Table 3 ).

In all subperiods (Panels A to $\mathrm{C}$ of Table 3), the net price-stabilization effect of dynamic VI is substantially higher during the continuous session $(31.26 \%, 43.34 \%$, and $40.27 \%$, respectively) than during the closing call auction $(21.62 \%, 23.45 \%$, and $14.47 \%$, respectively); the results in the pre- and post-event periods of 2015 are similar, indicating that the introductions of static VI and RE, and the expansion of the price-limit system had little effect on the net price-stabilization effect of dynamic VI (Panels A to C of Table 3) during the continuous session, and reduced somewhat the effect during the closing call auction (Panel C of Table 3). ${ }^{17}$ 
Table 3. Price-stabilization effect of VIs. This table describes the results of the binomial distribution analysis to evaluate the price-stabilization effect of VIs. Panels A to C present the results of dynamic VI during the post-event period in 2014, pre-event period in 2015, and post-event period in 2015, respectively, while Panel D presents the results of static VI during the post-event period in 2015. ${ }^{a}$ denotes a percentage measure of reversals of price changes, and ${ }^{b}$ denotes a percentage measure of continuations of price changes; both ${ }^{\mathrm{a}}$ and ${ }^{\mathrm{b}}$ are calculated by averaging I (call auction price potential execution price) $\times 100 /$ (potential execution price - last execution or last call auction price) $I$ over the set of reversals and continuations, respectively. ${ }^{c}$ denotes a percentage measure of net price stabilization, which is calculated by averaging - (call auction price - potential execution price) $\times 100 /$ (potential execution price - last execution or last call auction price) over the combined set of reversals and continuations. ${ }^{* *}$ denotes $1 \%$ statistical significance under the hypothesis that the probabilities of reversals and continuations of price changes are equal.

\begin{tabular}{|c|c|c|c|c|c|c|c|c|}
\hline & $\begin{array}{c}\text { No. of } \\
\text { Unchanged } \\
\text { Prices (A) }\end{array}$ & $\begin{array}{c}\text { No. of } \\
\text { Reversals of } \\
\text { Price } \\
\text { Changes (B) }\end{array}$ & $\begin{array}{l}\text { No. of Con- } \\
\text { tinuations of } \\
\text { Price } \\
\text { Changes (C) }\end{array}$ & $\begin{array}{l}\text { Total No. of } \\
\text { VI } \\
\text { Occurrences } \\
\text { (D) }\end{array}$ & $\begin{array}{l}\text { Stabilization } \\
\text { Ratio (\%) } \\
\text { (E) }\end{array}$ & $\begin{array}{c}\text { Price- } \\
\text { Stabilization } \\
\text { Effect (\%) } \\
\text { (F) }\end{array}$ & $\begin{array}{c}\text { Price- } \\
\text { Continuation } \\
\text { Effect (\%) } \\
\text { (G) }\end{array}$ & $\begin{array}{l}\text { Net Price- } \\
\text { Stabilization } \\
\text { Effect (\%) }^{c} \\
\text { (H) }\end{array}$ \\
\hline \multicolumn{9}{|c|}{ Panel A. Dynamic VI: Post-event period in 2014} \\
\hline $\begin{array}{l}\text { Continuous } \\
\text { session }\end{array}$ & 85 & 699 & 136 & 920 & $83.7^{* * *}$ & 44.42 & 36.35 & 31.26 \\
\hline $\begin{array}{l}\text { Closing call } \\
\text { auction }\end{array}$ & 66 & 65 & 17 & 148 & $79.3^{* * *}$ & 31.97 & 17.96 & 21.62 \\
\hline Total & 151 & 764 & 153 & 1068 & $83.3^{* * *}$ & 43.36 & 34.31 & 30.40 \\
\hline \multicolumn{9}{|c|}{ Panel B. Dynamic VI: Pre-event period in 2015} \\
\hline $\begin{array}{l}\text { Continuous } \\
\text { session }\end{array}$ & 38 & 715 & 85 & 838 & $89.3^{* * *}$ & 53.65 & 43.36 & 43.34 \\
\hline $\begin{array}{l}\text { Closing call } \\
\text { auction }\end{array}$ & 44 & 67 & 9 & 120 & $88.2^{* * *}$ & 27.98 & 10.22 & 23.45 \\
\hline Total & 82 & 782 & 94 & 958 & $89.2^{* * *}$ & 51.54 & 40.19 & 41.62 \\
\hline \multicolumn{9}{|c|}{ Panel C. Dynamic VI: Post-event period in 2015} \\
\hline $\begin{array}{l}\text { Continuous } \\
\text { session }\end{array}$ & 61 & 825 & 110 & 996 & $88.2^{* * *}$ & 53.18 & 56.54 & 40.27 \\
\hline $\begin{array}{l}\text { Closing call } \\
\text { auction }\end{array}$ & 61 & 41 & 15 & 117 & $73.2^{* * *}$ & 26.25 & 17.73 & 14.47 \\
\hline Total & 122 & 866 & 125 & 1113 & $87.3^{* * *}$ & 51.91 & 51.88 & 38.82 \\
\hline \multicolumn{9}{|c|}{ Panel D. Static VI: Post-event period in 2015} \\
\hline $\begin{array}{l}\text { Opening call } \\
\text { auction }\end{array}$ & 26 & 86 & 89 & 201 & 49.1 & 30.90 & 15.88 & 7.11 \\
\hline $\begin{array}{l}\text { Continuous } \\
\text { session }\end{array}$ & 849 & 2813 & 1842 & 5504 & $60.4^{* * *}$ & 11.10 & 11.94 & 1.98 \\
\hline $\begin{array}{l}\text { Closing call } \\
\text { auction }\end{array}$ & 45 & 26 & 20 & 91 & 56.5 & 16.21 & 7.30 & 5.99 \\
\hline Total & 920 & 2925 & 1951 & 5796 & $60.0^{* * *}$ & 11.73 & 12.08 & 2.21 \\
\hline
\end{tabular}

Over the post-event period in 2015, dynamic VI was modified by the addition of an RE mechanism (see Figure 1). To address potential offsetting effects, we recalculated the price stabilization and continuation, and net price-stabilization effect of dynamic VI using the order book, assuming that the call auction price would be the price exactly $2 \mathrm{~min}$ after the trigger of dynamic VI. The untabulated results are not different from those in Table 3; e.g., the net price-stabilization effect was $40.26 \%$ and $14.47 \%$ for the continuous session and closing auction, respectively. This indicates that the addition of the RE mechanism to dynamic VI had a negligible effect on the price stabilization, price continuation, and net price-stabilization effects. 
Panel D of Table 3 suggests that the stabilization effects of static VI are much weaker than those of dynamic VI. The stabilization effect of static VI is highest during the opening call auction, but it is still only about $7 \%$. In the case of static VI during the continuous session, the net price-stabilization effect is less than $2 \%$, indicating that static VI does not provide the intended cooling-off effect. These results in Panel D of Table 3 are consistent with Table 2, which shows that static VI has a much smaller effect of reducing volatility compared to dynamic VI. We further discuss the effectiveness of static VI in Section 8 with the price-limit system in consideration.

\subsection{Panel-Data Analysis as a Robustness Check}

Third, we conduct a robustness check. According to theoretical (e.g., Foucault et al 2005) and empirical (e.g., Kandel et al. 2012; Lei et al. 2020) studies, if the introduction of the closing call auction improves price accuracy, then the returns of close-to-open and open-to-close have a negative correlation since the closing call auction reduces much noise. Here, noise is caused by liquidity shocks or price manipulation, and the closing call auction corrects the noise. This result is analogous to the price reversal surrounding the VI occurrence (Eom et al. 2021).

Our robustness check tests whether the return between the last execution (last call auction) price and the potential execution price is negatively related with the return between the potential execution price and the call auction price for dynamic (static) VI. Even though this test cannot show the detailed dynamics of price reversal revealed by our main binomialdistribution analysis, it can clearly show the signs of a relationship.

We employed the following standard panel-data analysis (e.g., Eom et al. 2007), with the analyses for dynamic and static VIs performed separately over the respective subperiods.

$$
y_{i, t}=\beta_{0}+\beta_{1} x_{i, t}+\beta_{2} \ln \left(T S_{i, t}\right)+\beta_{3} \ln \left(\operatorname{MktCap}_{i, t}\right)+\alpha_{i}+\varepsilon_{i, t}
$$

where the subscript $i$ indexes individual firms, $t$ indexes the subperiods, $y$ is the return between the potential execution price and the call auction price, and $x$ is the return between the last execution (last call auction) price and the potential execution price for dynamic (static) VI. TS and MrkCap are control variables, denoting the trade size and firm size, respectively. $\alpha_{i}$ denotes individual firm-specific effects, and $\varepsilon_{i, t}$ is independently and identically distributed with zero mean and $\sigma_{\varepsilon}^{2}$ variance. We take the logarithm of TS and MrkCap since their distributions are skewed to the right.

Table 4 shows that the estimates of our key coefficient, $\beta_{1}$, are negative and statistically significant in all subperiods for dynamic and static VIs, and the coefficients for dynamic VI are much larger than those for static VI. ${ }^{18}$ This implies that there exists a price reversal surrounding the VI occurrences, indicating that both dynamic and static VIs have a pricestabilization effect, but that the price-stabilization effect of dynamic VI is much larger than that of static VI. The results of this robustness check confirm those of our main binomial-distribution analysis. 
Table 4. Panel-data analysis as a robustness check. This table provides the results of the following standard panel-data analysis, with the analyses for dynamic and static VIs performed separately over the respective subperiods. ${ }^{*}, * *$, and ${ }^{* * *}$ denote the $10 \%, 5 \%$, and $1 \%$ statistical significance, respectively. $y_{i, t}=\beta_{0}+\beta_{1} x_{i, t}+\beta_{2} \ln \left(T S_{i, t}\right)+\beta_{3} \ln \left(M k t C a p_{i, t}\right)+\alpha_{i}+\varepsilon_{i, t}$, where the subscript $i$ indexes individual firms, $t$ indexes the subperiods, $y$ is the return between the potential execution price and the call auction price, and $x$ is the return between the last execution (last call auction) price and the potential execution price for dynamic (static) VI. TS and MrkCap are control variables, denoting the trade size and firm size, respectively. $\alpha_{i}$ denotes individual firm-specific effects, and $\varepsilon_{i, t}$ is independently and identically distributed with zero mean and $\sigma_{\varepsilon}^{2}$ variance. We take the logarithm of TS and MrkCap, since their distributions are skewed to the right. Parentheses denote $t$-values.

\begin{tabular}{|c|c|c|c|c|}
\hline$\beta_{0}$ & $\beta_{1}$ & $\beta_{2}$ & $\beta_{3}$ & $\operatorname{Adj} R^{2}$ \\
\hline \multicolumn{5}{|c|}{ Panel A. Post-event period in 2014: Dynamic VI } \\
\hline $\begin{array}{c}0.0118 \\
(1.39)\end{array}$ & $\begin{array}{c}-0.2851 * * * \\
(-20.62)\end{array}$ & $\begin{array}{c}0.0008^{* * *} \\
(2.94)\end{array}$ & $\begin{array}{c}-0.0015^{* *} \\
(-1.97)\end{array}$ & 0.28 \\
\hline \multicolumn{5}{|c|}{ Panel B. Pre-event period in 2015: Dynamic VI } \\
\hline $\begin{array}{l}-0.0113 \\
(-1.41)\end{array}$ & $\begin{array}{c}-0.4182 \text { *** } \\
(-30.42)\end{array}$ & $\begin{array}{l}0.0003 \\
(1.19)\end{array}$ & $\begin{array}{c}0.0001 \\
(0.19)\end{array}$ & 0.49 \\
\hline \multicolumn{5}{|c|}{ Panel C. Post-event period in 2015: Dynamic VI } \\
\hline $\begin{array}{c}-0.0083 \\
(-1.16)\end{array}$ & $\begin{array}{c}-0.3433^{* * *} \\
(-22.28)\end{array}$ & $\begin{array}{c}0.0003 \\
(1.17) \\
\end{array}$ & $\begin{array}{l}-0.0001 \\
(-0.28)\end{array}$ & 0.31 \\
\hline \multicolumn{5}{|c|}{ Panel D. Post-event period in 2015: Static VI } \\
\hline $\begin{array}{l}-0.0054 \text { * } \\
(-1.77)\end{array}$ & $\begin{array}{c}-0.0460 * * * \\
(-16.18)\end{array}$ & $\begin{array}{c}-0.0008^{* * *} \\
(-5.71)\end{array}$ & $\begin{array}{c}0.0007^{* * *} \\
(3.38)\end{array}$ & 0.04 \\
\hline
\end{tabular}

\section{Price-Discovery Effect}

The other key goal of the KRX's introduction of VI was to improve price discovery. Specifically, we are interested in how much price uncertainty is resolved by VIs. To capture this fraction, we use Zimmermann's (2013) two-step regression model which is based on Corwin and Lipson (2000) and Chakrabarty et al. (2011): ${ }^{19}$

$$
\text { Step 1: } \ln \left(P_{i, \text { post }} / P_{i, \text { pre }}\right)=\alpha_{1}+\beta_{1} \times \ln \left(P_{i, \text { last }} / P_{i, \text { pre }}\right)+e_{i}
$$

$$
\text { Step } 2: \ln \left(P_{i, \text { auction }} / P_{i, \text { last }}\right)=\alpha_{2}+\beta_{2} \times e_{i}+\eta_{i}
$$

where $P_{i, \text { pre }}\left(P_{i, \text { post }}\right)$ denotes the reference price before (after) the VI is invoked, which is measured by the mean of the mid-price of the best bid and ask quotes during the ten minutes before the VI is invoked (after the call auction is completed). $P_{i, \text { last }}$ and $P_{i, \text { auction }}$ denote the last execution price before the VI is invoked and the call auction price, respectively. The subscript $i$ indexes individual firms, and $e_{i}$ and $\eta_{i}$ are residuals of each regression model.

In this two-step regression analysis, if the price change over the ten minutes before the VI occurrence fully reflects the new equilibrium price over the ten minutes after the resulting call auction, then in the first step $\alpha_{1}=0, \beta_{1}=1$, and $R^{2}=1$. Thus, $\beta_{1}<1$ $\left(\beta_{1}>1\right)$ implies that $P_{i, \text { last }}$ overshoots (undershoots) the short-term future equilibrium price and the degree of overshooting (undershooting) is more severe as the magnitude of $\beta_{1}$ deviates further from $1 .{ }^{20}$ In the second step, $\beta_{2}$ shows the expected price discovery of VI. If VI fully resolves the price uncertainty, then $\alpha_{2}=0, \beta_{2}=1$, and $R^{2}=1$. For example, if $\beta_{2}$ is positive, then it indicates that VI decreases the price uncertainty, i.e., improves price discovery; moreover, the reduction in uncertainty is greater as $\beta_{2}$ becomes closer to 1 . On the other hand, if $\beta_{2}$ is negative, it indicates that VI results in a deterioration of price discovery. We perform this analysis for dynamic and static VIs separately. ${ }^{21}$

Panels A to C of Table 5 show that for dynamic VI, $\beta_{1}$ ranges from 0.4128 to 0.4392 , which is positive but substantially smaller than one. The price greatly overshoots during 
the ten minutes before the VI invocation, indicating a high degree of price uncertainty in the market prior to the VI invocation. This is consistent with the strong positive correlation between VI occurrences and volatility shown in Section 5. By contrast, $\beta_{2}$ is positive and relatively close to one. It is highest during the post-event period in 2014 and statistically different from one at the $1 \%$ significance level, but it becomes closer to one in later subperiods in 2015. In the pre- and post-event periods in 2015, our results show that $\beta_{2}$ is 0.9280 and 1.0627, respectively, and they are not significantly different from one. These results suggest that dynamic VI resolves a substantial part of price uncertainty, and its effect is especially stronger in 2015. In other words, dynamic VI generates a notable effect on price discovery and price stabilization. Moreover, this beneficial effect is maintained even after the introduction of static VI, showing that both price-discovery and price-stabilization effects of dynamic VI were established at its introduction and were not substantially affected by the introduction of static VI.

Table 5. Price-discovery effect of VIs. This table provides the estimation results of the following two-step regressions, with the analyses for dynamic and static VIs performed separately over the respective subperiods. ${ }^{* *}$ and ${ }^{* *}$ denote the $5 \%$ and $1 \%$ statistical significance, respectively. Step 1 : $\ln \left(P_{i, \text { post }} / P_{i, \text { pre }}\right)=\alpha_{1}+\beta_{1} \ln \left(P_{i, \text { last }} / P_{i, \text { pre }}\right)+e_{i} ;$ Step $2: \ln \left(P_{i, \text { auction }} / P_{i, \text { last }}\right)=\alpha_{2}+\beta_{2} e_{i}+\eta_{i}$, where $P_{i \text {,pre }}\left(P_{i, p o s t}\right)$ denotes the reference price before (after) the VI is invoked, which is measured by the mean of the mid-price of the best quotes during the ten minutes before the VI is invoked (after the call auction is completed). $P_{i, \text { last }}$ and $P_{i, \text { auction }}$ denote the last execution price before the VI is invoked and the call auction price, respectively. The subscript $i$ indexes individual firms, and $e_{i}$ and $\eta_{i}$ are residuals of each regression model. Parentheses denote $t$-values and $k$ denotes the step.

\begin{tabular}{|c|c|c|c|c|c|}
\hline & $\alpha_{i}$ & $\beta_{k}$ & $\operatorname{Adj} R^{2}$ & $\begin{array}{c}\text { No. of } \\
\text { Observations }\end{array}$ & Prob. $>F$ \\
\hline \multicolumn{6}{|c|}{ Panel A. Post-event period in 2014: Dynamic VI } \\
\hline Step 1 & $\begin{array}{c}-0.0059 * * * \\
(-3.42)\end{array}$ & $\begin{array}{c}0.4392 * * * \\
(9.40)\end{array}$ & 0.1728 & 419 & $<2.2 \times 10^{-16}$ \\
\hline Step 2 & $\begin{array}{c}-0.0068^{* * *} \\
(-4.65)\end{array}$ & $\begin{array}{c}1.3508^{* * *} \\
(32.36) \\
\end{array}$ & 0.7145 & 419 & $<2.2 \times 10^{-16}$ \\
\hline \multicolumn{6}{|c|}{ Panel B. Pre-event period in 2015: Dynamic VI } \\
\hline Step 1 & $\begin{array}{c}0.0049^{* *} \\
(2.91)\end{array}$ & $\begin{array}{c}0.4361 * * * \\
(12.02)\end{array}$ & 0.2433 & 447 & $<2.2 \times 10^{-16}$ \\
\hline Step 2 & $\begin{array}{l}-0.0015 \\
(-1.02)\end{array}$ & $\begin{array}{c}0.9280 * * * \\
(20.79)\end{array}$ & 0.4915 & 447 & $<2.2 \times 10^{-16}$ \\
\hline \multicolumn{6}{|c|}{ Panel C. Post-event period in 2015: Dynamic VI } \\
\hline Step 1 & $\begin{array}{c}-0.0044^{* *} \\
(-3.19)\end{array}$ & $\begin{array}{c}0.4128^{* * *} \\
(10.93)\end{array}$ & 0.2037 & 464 & $<2.2 \times 10^{-16}$ \\
\hline Step 2 & $\begin{array}{c}-0.0062 * * * \\
(-5.36)\end{array}$ & $\begin{array}{l}1.0627^{* * *} \\
(26.82)\end{array}$ & 0.6081 & 464 & $<2.2 \times 10^{-16}$ \\
\hline \multicolumn{6}{|c|}{ Panel D. Post-event period in 2015: Static VI } \\
\hline Step 1 & $\begin{array}{c}0.0141^{* * *} \\
(26.52)\end{array}$ & $\begin{array}{c}-0.3087^{* * *} \\
(-39.01)\end{array}$ & 0.2548 & 4449 & $<2.2 \times 10^{-16}$ \\
\hline Step 2 & $\begin{array}{c}0.0266^{* * *} \\
(19.65)\end{array}$ & $\begin{array}{c}0.8984^{* * * *} \\
(23.05)\end{array}$ & 0.1065 & 4449 & $<2.2 \times 10^{-16}$ \\
\hline
\end{tabular}

Furthermore, these effects are not altered by the addition of an RE mechanism to dynamic VI. To address potential offsetting effects, we performed the same two-step regression analysis using the order book, assuming that the call auction price would be the price exactly 2 min after the trigger of dynamic VI. The results, not shown in a table for brevity, are consistent with those in Table $5 ; \beta_{1}$ and $\beta_{2}$ are 0.4242 and 0.7764 and significantly different 
from one at the $1 \%$ statistical significance level, respectively. This indicates that the addition of the RE mechanism to dynamic VI had a negligible effect on the price-discovery effect.

In Panel D of Table 5 , the results for static VI also show that $\beta_{1}$ and $\beta_{2}$ are all statistically significant, but their values-especially $\beta_{1}$-differ from those for dynamic VI. In particular, from Panels $\mathrm{A}$ to $\mathrm{C}$ of Table 5 , we find that $\beta_{1}$ for dynamic VI is positive with small differences across subperiods, but $\beta_{1}$ for static VI in Panel D of Table 5 is negative as -0.3087 . These results imply that the price during the ten minutes before static VI overshoots much more than that before dynamic VI. However, the positively significant $\beta_{2}$ which is closer to 1 indicates that static VI also contributes to resolving the price uncertainty. In the postevent period in 2015, both dynamic and static VIs have $\beta_{2}$ close to 1 (1.0627 and 0.8984, respectively). In untabulated results, however, we find that the hypothesis $\beta_{2}=1$ is rejected at the $1 \%$ significance level for static VI. Moreover, it is also notable that $\alpha_{2}$ is much larger (in absolute value) and $R^{2}$ is much lower in the case of static VI (10.65\%) compared to dynamic VI (60.81\%). These results suggest that static VI's contribution on price discovery is much smaller than that of dynamic VI.

\section{The Relationship of VIs with Price-Limit System}

In Sections 6 and 7, we found that dynamic VI more effectively stabilizes the price and brings a larger contribution on resolving price uncertainty and thus improving price discovery, compared to static VI. For the limited effect of static VI, we suspect that the price-limit system, which had existed in the market before static VI was introduced, may play a similar role in the market. Thus, we elaborate on the relationships between dynamic VI, static VI, and the price-limit system in this section.

We focus on two subperiods surrounding the 2015 event, when static VI was introduced and started to be in force, and the price limit was doubled from $\pm 15 \%$ to $\pm 30 \%$ : the pre-event period (8 April 2015 to 12 June 2015) and the post-event period (15 June 2015 to 21 August 2015). Analyzing the changes before and after the 2015 event will help us to better understand the economic function of static VI with respect to the price-limit system with the effect of dynamic VI controlled.

For each subperiod in 2015, we divide the VI occurrences into two groups by the direction of the price change: increasing or decreasing VIs. We define the positive (negative) price change that invoked the VI as "increasing (decreasing) dynamic VI". In other words, when the dynamic VI is invoked with an increase (decrease) of the potential execution price, then we classify it as increasing (decreasing) dynamic VI. "Increasing (decreasing) static VI" is defined in the same way. We also classify price-limit hits into upper and lower price-limit hits.

We use the following panel logit regression analysis (Equation (4)) to examine whether the occurrences of VIs affect the occurrences of price-limit hits:

$$
\begin{array}{ll}
\operatorname{Pr}\left(y_{i t}=1\right) & =F\left(\beta_{0}+\beta_{1} \operatorname{DVIUP}_{i t}+\beta_{2} \text { DVIDOWN }_{i t}+\beta_{3} \text { SVIUP }_{i t}+\right. \\
& \beta_{4} \text { SVIDOWN }_{i t}+\beta_{5} \ln \left(\text { PRC }_{i t}\right)+\beta_{6} \text { VOLATILITY }_{i t}+\beta_{7} \text { TURN }_{i t}+ \\
& \left.u_{t}+\alpha_{i}+e_{i t}\right)
\end{array}
$$

where $y_{i t}$ is a binary dependent variable having the value of 1 if the stock $i$ on day $t$ experiences a hit on either upper or lower price limit, and 0 otherwise. DVIUP $P_{i t}\left(D V I D O W N_{i t}\right)$ is the number of increasing (decreasing) dynamic VIs that the stock $i$ experiences on day $t$. $S V I U P_{i t}\left(S V I D O W N_{i t}\right)$ is the number of increasing (decreasing) static VIs that the stock $i$ experiences on day $t$. For control variables, we include the stock price $\left(\ln \left(P R C_{i t}\right)\right)$, intraday volatility $\left(V O L A T I L I T Y_{i t}\right)$, and turnover $\left(T U R N_{i t}\right)$, where VOLATILITY $Y_{i t}$ is computed by using the highest and lowest prices on a given day. $u_{t}$ and $\alpha_{i}$ capture the time- and fixed-effects, respectively. $e_{i t}$ is independently and identically distributed with zero mean and $\sigma_{e}^{2}$ variance. We estimated Equation (4) separately for the upper and lower price limits and in each subperiod.

Table 6 shows that the occurrences of both dynamic and static VIs are generally related to the occurrences of price-limit hits, especially the ones for the same direction of 
movement: the occurrences of upper price-limit hits are positively and more closely related to the occurrences of increasing dynamic or static VIs, while the occurrences of lower pricelimit hits are positively and more closely related to the occurrences of decreasing dynamic or static VIs. The results show that these relations became stronger in the post-event (Panel B) period in 2015 than the pre-event (Panel A) period in 2015.

Table 6. Panel logit analysis. This table provides estimation results for a panel logit regression model (Equation (4)). Panels A and B show the results for the pre- and post-event periods in 2015, respectively. Dependent variables are either upper or lower price-limit hits, which are the binary variable having the value of 1 if the stock $i$ at time $t$ experiences a hit on either upper or lower price limit, or 0 otherwise. DVIUP $P_{i t}\left(D V I D O W N_{i t}\right)$ is the number of increasing (decreasing) dynamic VIs that the stock $i$ experiences at time $t . S V I U P_{i t}\left(S V I D O W N_{i t}\right)$ is the number of increasing (decreasing) static VIs that the stock $i$ experiences at time $t$. For control variables, we include the stock price $\left(\ln \left(P R C_{i t}\right)\right)$, intraday volatility $\left(V O L A T I L I T Y_{i t}\right)$, and turnover $\left(T U R N_{i t}\right) .{ }^{*},{ }^{* *}$, and ${ }^{* * *}$ denote $10 \%$, $5 \%$, and $1 \%$ statistical significance, respectively.

\begin{tabular}{lcccc}
\hline \multirow{2}{*}{ Variable } & \multicolumn{2}{c}{ Upper Price-Limit Hits } & \multicolumn{2}{c}{ Lower Price-Limit Hits } \\
\cline { 2 - 4 } & Coefficient & $z$ & Coefficient & $z$ \\
\hline DVIUP & Panel A. Pre-event period in 2015 & & \\
DVIDOWN & $0.4758^{* *}$ & 2.45 & 0.2319 & 0.68 \\
In(PRC) & 0.0425 & 0.25 & 0.0323 & 0.11 \\
VOLATILITY & $-3.1103^{* * *}$ & -14.77 & $3.7305^{* * *}$ & 9.82 \\
TURN & $30.1273^{* * *}$ & 35.41 & $29.3607^{* * *}$ & 17.03 \\
\hline & $4.6534^{* * *}$ & 9.22 & -0.1689 & -0.32 \\
\hline DVIUP & Panel B. Post-event period in 2015 & & \\
DVIDOWN & $1.6965^{* * *}$ & 3.36 & 0.3484 & 0.08 \\
SVIUP & $-0.0071^{* * *}$ & -0.02 & $2.9220^{* * *}$ & 2.33 \\
SVIDOWN & $2.1976^{* * *}$ & 8.74 & -1.0825 & -1.58 \\
In(PRC) & $-1.4126^{* * *}$ & -6.69 & $1.6889^{* * *}$ & 2.30 \\
VOLATILITY & $-2.9877^{* * *}$ & -3.80 & $4.0696^{*}$ & 1.87 \\
TURN & $16.9507^{* * *}$ & 6.81 & 5.1778 & 0.65 \\
\hline
\end{tabular}

With regard to the upper price-limit hits, the effect of dynamic VI is limited only to the case of increasing dynamic VIs; This result occurs in both pre- and post-event periods in 2015, but the effect of increasing dynamic VI becomes much larger in the post-event period in 2015. By contrast, for static VI, Panel B of Table 6 shows that both increasing and decreasing static VIs are significantly related to upper price-limit hits and that their coefficients (2.1976 and -1.4126) are larger and more significant impacts on the upper price-limit hits than the corresponding increasing and decreasing dynamic VIs. These results imply that the occurrences of increasing (decreasing) static VIs increase (decrease) the probability of the occurrences of upper price-limit hits by $0.5494(0.3532){ }^{22}$

In the case of the lower price-limit hits, the occurrences of increasing dynamic VIs have no effect on the lower price-limit hits in both subperiods in 2015 . The occurrences of decreasing dynamic VIs also have no effect on the lower price-limit hits in the pre-event period in 2015, but they become significant in the post-event period in 2015 after static VI was implemented. In particular, in the post-event period in 2015, the coefficient of lower price-limit hits on decreasing dynamic VIs is 2.9220. This pattern appears in static VI as well. The coefficient of lower price-limit hits on decreasing static VIs is 1.6889, even smaller than on decreasing dynamic VIs, ${ }^{23}$ while that on increasing static VIs is insignificantly negative. This result for static VI contrasts somewhat to that for static VI in the case of the upper price-limit hits; the latter shows the significant contribution of both increasing and decreasing static VIs to the occurrences of upper price-limit hits. However, the results for static VI in both cases suggest that static VI and the price-limit system are triggered by the 
same kind of circumstances. Furthermore, the result for static VI in the case of the lower price-limit hits may be indirect evidence that static VI contributes to price stability through a cooling-off effect: many occurrences of static VI result in failing to hit the price limit.

Intraday volatility has a positive coefficient regardless of periods and price limits. The price shows a negative relation with the upper price-limit hits, but a positive and statistically significant relationship with the lower price-limit hits. Lastly, the turnover shows a significant relationship with the upper price-limit hits, but it appears to be insignificantly related to the lower price-limit hits. This asymmetric relationship can be attributed to the stylized fact that the trading volume in the Korean stock markets does not increase a lot when the price decreases (see Kim et al. 1999).

\section{Conclusions}

The KRX's sequential introductions of dynamic and static VIs were intended to improve price formation and to limit risk to investors during brief periods of abnormal volatility for individual stocks. In the Korean stock markets, the VI was built on top of a pre-existing price-limit system that was intended to serve similar purposes.

The sequential introductions of dynamic and static VIs to the Korean stock markets allowed us to separate the effects of these two types of VIs and compare their effectiveness. Moreover, the pre-existing price-limit system on the Korean stock markets allowed us to separate the effects of price-limit systems and VIs.

Using intraday transaction data, we first confirm that both VIs are invoked more often in small, low-priced, and highly volatile stocks. A bit surprisingly, however, static VI occurs more to liquid stocks whereas dynamic VI occurs, as expected, more to illiquid stocks. Next, more importantly, we find that both VIs have a contribution on price stabilization and price discovery, but the larger benefits arise from dynamic VI than from static VI. It is also noteworthy that for price stabilization, the effect during continuous trading is significantly higher than during the closing auction. Lastly, for the limited effect of static VI, we suggest that static VI functions similarly to the pre-existing price-limit system and this accounts for its limited incremental benefit.

Author Contributions: Conceptualization, K.S.E. and S.C.L.; methodology, K.S.E., K.Y.K. and J.-H.P.; formal analysis, J.-H.P.; investigation, K.S.E., K.Y.K., S.C.L. and J.-H.P.; data curation, K.S.E., S.C.L. and J.-H.P.; writing-original draft preparation, K.S.E. and K.Y.K.; writing-review and editing, K.S.E., K.Y.K. and J.-H.P.; project administration, K.S.E. All authors have read and agreed to the published version of the manuscript.

Funding: This research received no external funding.

Data Availability Statement: The data are available by purchase from the KRX (https:/ / data.krx.co. $\mathrm{kr}$, accessed on 27 January 2022).

Conflicts of Interest: The authors declare no conflict of interest.

\section{Notes}

1 An RE trading mechanism is an integral part of a call auction mechanism. The ending time of the call auction is not fixed, but extended under certain circumstances for a brief randomly-chosen span of time less than or equal to a "maximum duration" such as $30 \mathrm{~s}$ or one minute (Eom et al. 2021). Deutsche Börse Cash Market (2020) states that the Deutsche Börse (DB) introduced a RE mechanism to avoid manipulative orders. Eom et al. (2021) show that the KRX RE mechanism helps to discourage spoofing at the open and close.

2 Vis are considered as implicit dynamic price-limit systems, compared to the explicit price-limit systems. In other words, reversal in these two price changes is an indication of stabilization; see Sections 6.2 and 6.3.

4 The KRX is comprised of two equity markets, KOSPI and KOSDAQ. KOSPI is the main board, while KOSDAQ is the new (or growth) market which provides funding mainly to IT-related, newly incorporated, and/or innovative small- and medium-sized enterprises (SMEs).

5 The LULD is an extreme form of static VI, specifically focusing on preventing the recurrence of cases similar to the Flash Crash in 2010. It applies a rolling price limit to individual stocks, using price bands ( 5 or $10 \%$ ) calculated over the previous five minutes trading (Eom et al. 2021). 
6 The introductions of these KRX rules were very different from the staggered introductions of the single-stock trading pauses (SSTP) or the Tick Size Pilot Program (TSPP) in the U.S. stock markets. These U.S. rules were applied differently to pre-determined groups of firms, so that test groups and a control group can be clearly identified. As a consequence, the SSTP and, especially, the TSSP have sparked research using the difference-in-difference (DID) analysis (e.g., Hautsch and Horvath 2019; Chung et al. 2020; Brogaard and Pan Forthcoming; among many others). In contrast, the KRX introduced the rules sequentially, but applied them to all firms unilaterally, so that we cannot conduct a DID analysis. However, the sequential introductions of the different aspects of VI do allow us to analyze the effects of the individual VI components (see footnote 13 in Section 6.2 for more discussion).

Eom et al. (2021) analyze the (conditional) RE mechanism on the KRX, a built-in component of the VI, and show that its price-discovery effect could be different depending on trading session.

$8 \quad$ Broadly defined circuit breakers theoretically lead to a reduction in transactional risk (Greenwald and Stein 1991); stabilization of derivatives markets (Chowdhry and Nanda 1998); and the magnet effect whereby price limits become self-fulling (Subrahmanyam 1994). Empirically, market-wide circuit breakers bring about the magnet effect and curtailed trading activity (Goldstein and Kavajecz 2004). Price limits cause delayed price discovery, volatility spillover, delayed trading, and the magnet effect (e.g., Kim and Rhee 1997; Cho et al. 2003; among many others). For a comprehensive survey, please see Sifat and Mohamad (2019).

A limitation of their analysis is that they treat all data equally for the analyses despite the fact that those trading venues are very different in parameters and characteristics.

During the two years, 2014 and 2015, there were two other changes in the KRX; the KRX decreased the transaction unit and adjusted the rules on basket trading on 2 June 2014, and revised the call auction system during the off-hours trading period on 17 November 2014. We avoided these dates in choosing our test periods, and thus precluded any possible confounding.

At the end of 2014, the KRW/USD rate was 1088.50 and the exchange rate did not change dramatically during our sample period. According to the exchange rate at the end of 2014, $1000 \mathrm{KRW}$ was about 0.92 USD.

The variance-ratio test of Lo and MacKinlay (1988) could be another candidate to test the price-stabilizing effect of VIs: testing whether prices follow a random walk before and after each VI occurrence. However, our sample consists of too few observations over 30 (or 10) min to calculate a meaningful variance ratio during a given hour before and after the VI occurrence. Furthermore, the variance-ratio test is not appropriate in the high-frequency data since the intraday volatility is not stable (Andersen et al. 2001).

Since our interest is the effect of invocation of VIs on price stabilization, an event study focused on the VI invocations is the most natural way to address the problem. One might argue that we should use, as a control group, trades that occurred before the KRX implemented VIs. However, it is not possible to study the VIs, especially the potential execution price in our analyses, in the period before either dynamic or static VI was implemented. Within the extensive literature, there are only a handful of papers that use a DID approach (see footnote 6 for references). As mentioned in footnote 6, these papers are able to do this only because of the staggered introductions of the SSTP or the TSPP. Their setting is very unusual in providing natural control and test groups. To alleviate concerns about methodology, we also considered constructing the control group of stocks that experienced a large price change but not large enough to invoke the VI (e.g., 1.9\%) before the adoption of each VI. However, we found that the number of observations is too small (e.g., 40 in 2014 and 76 in 2015) to implement a meaningful analysis by the DID approach.

If the last execution (last call auction) price fails to properly reflect the market demand, but the potential price is an accurate one, then the transaction should be completed at the potential price, in which the VIs are not required at all.

15 In untabulated results, we also test the price-stabilization effect of static VI using the last execution price instead of the last call auction price and find that the results are qualitatively the same.

16 A trinomial analysis could be considered. In this case, however, an additional assumption would be needed; no new information that might affect the price arrived during the VI session, for which "we cannot disentangle the effects of the [VI] session and the informational arrival, and in particular cannot assign probabilities to the three possibilities (continuation, reversal, no change). However, there is a natural distribution, 50/50, over two possibilities (continuation and reversal), allowing us to use the binomial distribution for the price-stabilization effect of [VI] trading mechanism" (see Eom et al. 2021).

The net price-stabilization effect of dynamic VI during the continuous session is higher in the pre-event period in 2015 than in the post-event period of 2014; since there was no change in the trading rules between those periods, this suggests that the increase reflects some change in market conditions rather than a change in trading rules.

The coefficients of control variables, trade size and firm size, are generally very small and statistically weak. The coefficient signs in dynamic VI are generally intuitive. However, those in static VI seems to be related to the difference of opinion among traders as explained in Section 5.

19 This methodology is slightly different from that of Corwin and Lipson (2000). They focus on explaining whether " $P_{i, a u c t i o n}$ reflects some information not captured in $P_{i, l a s t}$ ".

20 Put differently, " $\beta_{1}>1$ suggests that returns exhibit continuations from before to after $\left[\left(P_{i, \text { last }}\right)\right]$ and $\beta_{1}<1$ suggests that returns exhibit reversals. Barclay and Hendershott (2003) provide an alternative interpretation of the slope coefficient. They note that if $\left[\left(P_{i, l a s t}\right)\right]$ is measured with error, the slope coefficient will be reduced. Thus, for $\beta_{1}<1$, the magnitude of the coefficient provides an estimate of the signal-to-noise ratio for $\left[\left(P_{i, l a s t}\right)\right]^{\prime \prime}$ (see Chakrabarty et al. 2011). 
The coefficients in step 2 should be interpreted in the context of those in step 1. Annex H in Guillaumie et al. (2020) provide a useful graphical explanation for the implications of our two-step regression model.

In a panel logit regression model, the marginal effect of each regressor is $\Lambda\left(x^{\prime} \beta\right)\left[1-\Lambda\left(x^{\prime} \beta\right)\right] \beta$, where $\Lambda$ is the cumulative logistic distribution function. Since the mean of the logit distribution is zero, we set $x^{\prime} \beta=0$. Hence, $\Lambda(0)[1-\Lambda(0)]=0.25$, and the marginal effect of each regressor is $0.25 \beta$. Substitute $0.25 \beta$ for each $\beta$ coefficient (see Greene 2000, p. 817 ).

Panel B of Table 1 shows that static VIs were much more frequently invoked than dynamic VIs in the post-event period in 2015; for example, static VIs were invoked five times more than dynamic VIs in terms of the total number of VI occurrences. Taking this into account, we expect that the actual contribution of static VI could be somewhat notable.

\section{References}

Abad, David, and Roberto Pascual. 2010. Switching to a temporary call auction in times of high uncertainty. Journal of Financial Research 33: 45-75. [CrossRef]

Alderighi, Stefano, Pedro Gurrola-Perez, Kaitao Lin, and Bill Speth. 2021. Circuit Breakers and Other Market Safeguards. London: World Federation of Exchanges.

Andersen, Torben, Tim Bollerslev, and Ashish Das. 2001. Variance-ratio statistics and high-frequency data: Testing for changes in intraday volatility patterns. Journal of Finance 56: 305-27. [CrossRef]

Barclay, Michael J., and Terrence Hendershott. 2003. Price discovery and trading after hours. Review of Financial Studies 16: 1041-73. [CrossRef]

Brady, Nicholas F. 1988. Report of the Presidential Task Force on Market Mechanisms; Washington, DC: Government Printing Office.

Brogaard, Jonathan, and Jing Pan. Forthcoming. Dark pool trading and information acquisition. Review of Financial Studies.

Brugler, James, Oliver Linton, Joseph Noss, and Lucas Pedace. 2018. The Cross-Sectional Spillovers of Single Stock Circuit Breakers. London: Bank of England.

Chakrabarty, Bidisha, Shane A. Corwin, and Marios A. Panayides. 2011. When a halt is not a halt: An analysis of off-NYSE trading during NYSE market closures. Journal of Financial Intermediation 20: 361-86. [CrossRef]

Cho, David D., Jeffrey Russell, George C. Tiao, and Ruey Tsay. 2003. The magnet effect of price limits: Evidence from high-frequency data on Taiwan Stock Exchange. Journal of Empirical Finance 10: 133-68. [CrossRef]

Chowdhry, Bhagwan, and Vikram Nanda. 1998. Leverage and market stability: The role of margin rules and price limits. Journal of Business 71: 179-210. [CrossRef]

Chung, Kee H., Albert J. Lee, and Dominik Rösch. 2020. Tick size, liquidity for small and large orders, and price informativeness: Evidence from the tick size pilot program. Journal of Financial Economics 136: 879-99. [CrossRef]

Corwin, Shane A., and Marc L. Lipson. 2000. Order flow and liquidity around NYSE trading halts. Journal of Finance 55: 1771-801. [CrossRef]

Deutsche Börse Cash Market. 2020. Market Model for the Trading Venue Xetra ${ }^{\circledR}$ : T7 Release 8.1. Frankfurt am Main: Deutsche Börse.

Diether, Karl B., Christopher J. Malloy, and Anna Scherbina. 2002. Difference of opinion and the cross section of stock returns. Journal of Finance 57: 2113-41. [CrossRef]

Eom, Kyong Shik, Jangkoo Kang, and Kyung Yoon Kwon. 2017. PIN, adjusted PIN, and PSOS: Difference of opinion in the Korean stock market. Asia-Pacific Journal of Financial Studies 46: 463-90. [CrossRef]

Eom, Kyong Shik, Jinho Ok, and Jong-Ho Park. 2007. Pre-trade transparency and market quality. Journal of Financial Markets 10: 319-41. [CrossRef]

Eom, Kyong Shik, Kyung Yoon Kwon, and Jong-Ho Park. 2021. Effectiveness of the conditional random-end trading mechanism on the Korea Exchange: Normal trade and Option Shock. Journal of Futures Markets 41: 1545-68. [CrossRef]

Foucault, Thierry, Ohad Kadan, and Eugene Kandel. 2005. Limit order book as a market for liquidity. Review of Financial Studies 18: 1171-217. [CrossRef]

Goldstein, Michael A., and Kenneth A. Kavajecz. 2004. Trading strategies during circuit breakers and extreme market movements. Journal of Financial Markets 7: 301-33. [CrossRef]

Greene, William H. 2000. Econometric Analysis, 4th ed. Upper Saddle River: Prentice Hall.

Greenwald, Bruce C., and Jeremy C. Stein. 1991. Transactional risk, market crashes, and the role of circuit breakers. Journal of Business 64: 443-62. [CrossRef]

Guillaumie, Cyrille, Giuseppe Loiacono, Christian Winkler, and Steffen Kern. 2020. Market Impacts of Circuit Breakers: Evidence from EU Trading Venues. Paris: ESMA.

Hautsch, Nikolaus, and Akos Horvath. 2019. How effective are trading pauses? Journal of Financial Economics 131: 378-403. [CrossRef]

Kandel, Eugene, Barbara Rindi, and Luisella Bosetti. 2012. The effect of a closing call auction on market quality and trading strategies. Journal of Financial Intermediation 21: 23-49. [CrossRef]

Kim, In Joon, Tong Suk Kim, and Won Tark Doh. 1999. The relationship between price changes and volume: The impact of market microstructure. Journal of Korean Financial Studies 24: 273-99. (In Korean).

Kim, Kenneth A., and S. Ghon Rhee. 1997. Price limit performance: Evidence from Tokyo Stock Exchange. Journal of Finance 52: 885-901. [CrossRef]

Lei, Adrian C. H., Xiaorong Ma, and Martin H. Y. Yick. 2020. Callable bull/bear contracts, call auction sessions, and price manipulations: Evidence from Hong Kong. Journal of Futures Markets 40: 1731-50. [CrossRef] 
Lo, Andrew W., and A. Craig MacKinlay. 1988. Stock market prices do not follow random walks: Evidence from a simple specification test. Review of Financial Studies 1: 41-66. [CrossRef]

Sifat, Imtiaz Mohammad, and Azhar Mohamad. 2019. Circuit breakers as market stability levers: A survey of research, praxis, and challenges. International Journal of Finance \& Economics 24: 1130-69.

Subrahmanyam, Avanidhar. 1994. Circuit breakers and market volatility: A theoretical perspective. Journal of Finance 49: 237-54. [CrossRef]

The Government Office for Science. 2012. Foresight: The Future of Computer Trading in Financial Markets; London: The Government Office for Science.

Zimmermann, Kai. 2013. Price Discovery in European Volatility Interruptions. Frankfurt am Main: Goethe University Frankfurt am Main. 